\title{
Los aspectos esenciales del Programa Penal de la Constitución en Chile
}

\section{POR JEAN PIERRE MATUS ACUÑA $(*)$}

\begin{abstract}
Sumario: I. Introducción.- II. El programa penal de la Constitución chilena: principios de legalidad, proporcionalidad, culpabilidad y debido proceso como únicos criterios de legitimación del derecho penal.- III. Función de las penas y prevención especial positiva como única finalidad constitucionalmente reconocida de las penas privativas de la libertad.- IV. Bibliografía.
\end{abstract}

Resumen: el texto sostiene que, en una democracia constitucional como la chilena, los únicos fundamentos del derecho penal y de la imposición de las penas han de encontrarse en la normativa constitucional vigente. Ellos son los principios de legalidad, proporcionalidad, culpabilidad y debido proceso. Se descartan así las teorías tradicionales del ius puniendi y los fundamentos sociológicos o de otro tipo dominantes en la literatura.

Palabras claves: ius puniendi - Constitución - legalidad - proporcionalidad debido proceso

\section{The essential aspects of the Chilean Constitution Penal Program}

Abstract: the text maintains that, in a constitutional democracy such as Chile, the only foundations of criminal law and the imposition of penalties must be established in the current constitutional regulations. They are the principles of legality, reserve and due process. Thus, the traditional theories of ius puniendi and the sociological or other dominant foundations in literature are discarded.

Keywords: Ius puniendi - Constitution - legality - reserve - due process

(*) Prof. Titular de Derecho Penal, Universidad de Chile. Dr. en Derecho por la Universidad Autónoma de Barcelona. Becario post-doctoral de la Fundación Alexander v. Humboldt en la Universidad de Göttingen. 


\section{Introducción}

La premisa principal de este trabajo es la siguiente: si la Constitución, con su sistema de garantías y sus referencias a los tratados sobre derechos humanos, es la norma fundamental en las sociedades occidentales democráticas, es a las reglas y principios que en ella se encuentran y a que ella remiten donde deben encontrarse los fundamentos y límites de un sistema de derecho derivado, como lo es el derecho penal. Ello significa que el legislador democrático no es completamente libre para sancionar cualquier conducta, hecho o estado con cualquier consecuencia penal que estime, sino que se encuentra limitado por las normas y principios de la Constitución (democrática), pero no por criterios subjetivos, como las exigencias funcionalistas derivadas de la idea que se tenga de sistema social à la Jakobs; de "estructuras lógico-objetivas" à la Welzel; de ideas abstractas e ideales de justicia, como las de Kant y Hegel; o su eficacia instrumental, à la Bentham, etc.

Esta vinculación positiva del derecho penal con la Constitución, que legitima su formación o aceptación democrática, asignándole la función material de garantizar los derechos, bienes e instituciones que en la ella se establecen, con pleno respeto al debido proceso, se puede identificar con la llamada orientación sustancial o teleológica sobre el rol de la Constitución en el derecho penal, o Escuela de Bolonia, originada en los aportes del profesor de dicha Universidad, Franco Bricola (Donini, 2011, p. 47). Esta aproximación permite reconocer la existencia del mentado Programa Penal de la Constitución como derecho positivo vinculante y de carácter superior, cuyos principios deben servir de guía o marco para determinar la validez, interpretación y aplicación del derecho penal, particularmente en la selección de los bienes jurídicos a proteger (que se limitarían a los constitucionalmente reconocidos), en contraposición a la restricción que ello supone a la libertad personal, valor que se entiende como superior dentro del ordenamiento jurídico(1).

En el presente artículo se describen algunas de las consecuencias de asumir el Programa Penal de la Constitución como criterio de legitimación del derecho

(1) Más adelante se explicará que, con todo, en este punto nuestra propuesta difiere parcialmente con la de Bricola (1973, p. 16), pues según el texto expreso de la Constitución chilena, ella autoriza la protección penal no solo de los derechos y garantías individuales, sino de todos bienes, derechos, garantías e instituciones constitucionalmente reconocidas. Esta variante del constitucionalismo que aquí se rechaza no solo no puede sustentarse en nuestro texto fundamental, sino también es contraria a la existencia del llamado derecho penal trasnacional, reconocido en múltiples tratados de nivel normativo semejante a los de derechos humanos y que impone obligaciones de sancionar penalmente conductas que, por ejemplo, dicen relación con la protección de los sistemas económicos o la prohibición del consumo de ciertas drogas, cuya reconducción directa a la protección de derechos fundamentales no siempre parece sencilla. 
penal en el derecho chileno, a través del respeto de los principios de legalidad, proporcionalidad, culpabilidad y debido proceso en el caso chileno, entendiendo que estos efectos, en la medida que su mayoría se encuentran referidos también a los derechos y garantías consagrados en los Tratados internacionales sobre Derechos Humanos, se mantendrán - al menos en sus mínimos- en cualquier otro nuevo texto constitucional que se apruebe en el actual proceso constituyente(2).

\section{El programa penal de la Constitución chilena: principios de legalidad, proporcionalidad, culpabilidad y debido proceso como únicos criterios de legitimación del derecho penal}

Lo distintivo de las leyes que se consideran como penales o criminales en los diversos ordenamientos jurídicos es que imponen un mal que recae sobre el cuerpo de una persona natural o consiste en la privación de derechos o bienes de una persona natural o jurídica, sin que dicho mal o privación de derechos o bienes esté condicionado a, o consista en la reparación de un daño exigida por un particular; o esté condicionado a, o consista en privaciones y restricciones de derechos aplicadas temporalmente para forzar el cumplimiento de una obligación determinada que cesa con su cumplimiento (Matus y Ramírez, 2015, p. 117). Y ese mal se impone en un proceso público, donde el interés del Estado es preponderante a la hora de institucionalizar los mecanismos de persecución, sanción y ejecución, en el entendido que "cualquier delito, aunque privado, ofende a la sociedad" y por ello el soberano tiene la "necesidad de defender el depósito de la salud pública de las particulares usurpaciones” (Beccaria, 1774, pp. 42 y 9).

Aceptada la existencia del derecho penal como entidad jurídica positiva, es necesario tratar, siquiera someramente, el problema de su legitimidad política: ¿Corresponde recurrir a esta clase de consecuencias jurídicas para sancionar conductas que importan exclusivamente lesión a intereses personales?, ¿se debe limitar esta clase de sanciones a quien lesiona la libertad, la propiedad o la existencia de las personas?, ¿se puede recurrir a ellas para proteger la existencia de la sociedad y la forma del Estado?, ¿se admite que el derecho penal proteja los intereses de

(2) El texto resume en esta parte el capítulo 2 de nuestro Manual de Derecho Penal Chileno (Matus y Ramírez, 2021), con ciertas modificaciones de relevancia, sobre todo respecto a la denominación del principio de reserva que ahora llamamos derechamente como principio de "proporcionalidad" y la identificación del principio de culpabilidad como uno de carácter independiente del de legalidad, donde se incorporaba en el texto de referencia. Sobre la necesidad y los cambios posibles en este nuevo proceso constituyente, ver Durán (2015). Antes, en Chile, la vinculación positiva del derecho penal con los principios de reserva y legalidad fue anticipada por Novoa (1987, p. 25), Mera (2005), Matus (2018), y ahora es promovida con fuerza por Fernández C. (2010) y Durán (2011). Incluso es reconocida tanto por la doctrina tradicional (Etcheberry, 1998, p. 65; Cury, 2020, p. 105), como por algunos autores marcadamente funcionalistas (Piña, 2005, p. 427). 
una Iglesia o de ciertas doctrinas morales, castigando el pecado y el vicio?, ¿es admisible para regular el comportamiento económico o conseguir una mejor distribución de la riqueza, proteger determinadas industrias o una forma particular de organización económica del Estado?, ¿se puede torturar al imponer un castigo o para obtener una confesión?, ¿ toda forma procedimental es legítima si está legitimada la amenaza de una pena?, etc.

La doctrina penal tradicional, cuyo desarrollo es anterior al de los Estados constitucionales actuales y, además, no se preocupa mayormente de los aspectos procesales, suele responder a estas preguntas afirmando que existiría algún criterio de legitimación universal y abstracto, ajeno al derecho positivo, que harían posible esbozar un juicio del estilo "la norma que castiga el hecho X con la pena $\mathrm{Y}$ es legítima o ilegítima, porque ese hecho $\mathrm{X}$ puede o no puede ser penalmente sancionado, y en caso afirmativo, puede o no imponerse esa pena $Y$, según los criterios de legitimación $\mathrm{W}$ y $\mathrm{Z}$ adoptados, respectivamente". Entre dichos criterios se mencionan el de la protección de bienes jurídicos, normas de cultura, valores éticos sociales, la vigencia de la norma social, o la promoción de ciertos valores políticos o morales. De este modo, la pena aparece como respuesta "justa" o "necesaria" para castigar o prevenir esas conductas, según los criterios de justificación que se adopten. Esta es la llamada "presunción del castigo" (Lorca, 2019, p. 179). Lamentablemente, como el desarrollo histórico demuestra, no solo no es claro que la pena sea la única respuesta ante tales conductas, sino que la búsqueda o aceptación de los criterios que las definen como merecedoras de penas, ajenos a la existencia de una sociedad democrática, no ha pasado de ser una racionalización de las preferencias subjetivas de quienes los afirman en un momento y lugar dados para sostener la legitimidad de un ordenamiento concreto, incluyendo los de la dictadura nacionalsocialista en Alemania, entre 1933 y 1945, las latinoamericanas de la década de 1970, el derecho penal monárquico, el revolucionario, etc.

Aquí se adopta, en cambio, un punto de partida normativo de derecho positivo - en el sentido de basado en la Constitución como norma fundamental y superior del derecho positivo vigente y las leyes dictadas en su conformidad-, e históricamente condicionado a la existencia de nuestra actual sociedad democrática, inmersa en una comunidad de naciones que acepta como único criterio legitimador del ejercicio de la soberanía nacional el respeto de los derechos y garantías contemplados en los tratados internacionales sobre derechos humanos vigentes. En dichos tratados se contemplan disposiciones jurídicas que hacen inútil cuestionarse, a nivel de derecho positivo, sobre la bondad o conveniencia política de su adopción o sobre su compatibilidad o no con determinadas doctrinas morales o políticas. En este cuerpo normativo las principales propuestas de Beccaria - revolucionarias a fines del siglo XVIII- son parte de las bases jurídicas de los Estados que adhieren a él y lo hacen parte de su ordenamiento constitucional: el principio de legalidad, 
la finalidad preventiva de las penas, la proporcionalidad entre delitos y penas, la reducción del empleo de la pena de muerte y la prohibición de la tortura (Etcheberry, 2011, p. 10). Y, lo más relevante, desde el punto de vista normativo, para su interpretación y aplicación en los tribunales locales, es "la imposibilidad de desconocerlos o modificarlos unilateralmente", según lo dispuesto en el artículo 27 de la Convención de Viena sobre el derecho de os Tratados (Fernández, 2006, p. 31).

Desde este punto de vista, se concibe al derecho penal como uno de los instrumentos de que dispone el Estado para servir a las personas y promover el bien común, creando "las condiciones sociales que permitan a todos y a cada uno de los integrantes de la comunidad nacional su mayor realización espiritual y material posible, con pleno respeto a los derechos y garantías" que la Constitución y los tratados internacionales ratificados por Chile establecen (artículos 1 y 5 de la Constitución Política de la República, en adelante CPR). Luego, para nosotros, la legitimidad o validez de una disposición penal y su aplicación al caso concreto proviene exclusivamente de su conformidad con la Constitución en cuatro aspectos fundamentales: 1) debe ser establecida o estar reconocida democráticamente, de conformidad con las exigencias formales y materiales que la propia Constitución establece (principio de legalidad); 2) debe ser idónea para la protección de bienes, derechos, garantías e instituciones constitucionalmente reconocidas y la pena dispuesta orientada a la reintegración social del condenado, de manera que pueda salvar la barrera del test de proporcionalidad constitucional, tanto en su formulación al limitar con la amenaza penal otros derechos y garantías como en la naturaleza de las penas que establece (principio de proporcionalidad); 3) debe excluirse toda presunción de derecho de culpabilidad y asegurar que la imposición de la pena sea precedida por la prueba de la existencia de una relación subjetiva entre el agente y el hecho que legitime sancionarlo por haberlo originado o depender de él su realización, excluyendo el versari in re illicita y la responsabilidad penal objetiva (principio de culpabilidad); y 4) su aplicación a un caso concreto y la consecuente imposición de una pena, solo será legítima si también el proceso en que materialmente se impone es conforme con las garantías y derechos constitucionales (principio del debido proceso). Desde nuestra perspectiva, además, estos requisitos de legitimidad no constituyen un conjunto de principios más o menos abstractos para enarbolar como crítica externa al derecho vigente, sino los fundamentos de las acciones constitucionales existentes para su alegación en el derecho positivo: recursos de amparo (artículo $21 \mathrm{CPR}$ ), nulidad (artículo 373 a) del Código Procesal Penal, en adelante CPP), inaplicabilidad e inconstitucionalidad (artículo 93 № 6 y 7 CPR).

El principio de legalidad legitima positiva y normativamente la forma de creación y aplicación del derecho penal, subordinando las decisiones del legislador democrático a los límites que establece el artículo 19 N. ${ }^{\circ} 3$ incs. 7, 8 y 9 CPR: "La ley no podrá presumir de derecho la responsabilidad penal"; "Ningún delito se 
castigará con otra pena que la que señale una ley promulgada con anterioridad a su perpetración, a menos que una nueva ley favorezca al afectado" y "Ninguna ley podrá establecer penas sin que la conducta que se sanciona esté expresamente descrita en ella" (nullum crimen, nulla poena sine lege). De allí se deriva el principio de legalidad, como garantía formal, en el sentido de que solo por ley aprobada por el Congreso Nacional se puede establecer delitos y a ella deben someterse los tribunales, el Ministerio Público y la doctrina penal en una sociedad democrática, respetuosa de la separación de poderes y ajena a las experiencias históricas de manipulación del sistema legal en beneficio de una clase, doctrina moral, política o ideología determinadas (Politoff, 1978). Como garantía material, el principio de legalidad exige que dichas leyes describan expresamente las conductas que sancionan, no puedan tener efectos perjudiciales retroactivamente, o sancionar estados personales o meros pensamientos no expresados, ni meros movimientos corporales o hechos sin vinculación a la subjetividad del agente (principio de culpabilidad). Estos principios permiten validar no solo la creación de las leyes penales, sino también las propuestas de interpretación que de ellas se hagan, en la medida que sean conformes a la Constitución y los principios que reconoce.

El principio de proporcionalidad legitima positivamente el poder de creación del legislador y de interpretación aplicación de las leyes, subordinándolo a la protección de bienes, derechos, garantías e instituciones constitucionalmente reconocidas; y también, negativamente, al subordinarlo al respeto a los derechos y garantías constitucionales y a las contempladas en los Tratados de derechos Humanos vigentes, pues como señala el artículo 19 № 26 CPR, la Carta Magna garantiza a todas las personas, "la seguridad de que los preceptos legales que por mandato de la Constitución regulen o complementen las garantías que ésta establece o que las limiten en los casos que ella lo autoriza, no podrán afectar los derechos en su esencia, ni imponer condiciones, tributos o requisitos que impidan su libre ejercicio". De allí se derivan las limitaciones de idoneidad y necesidad para el establecimiento de hechos punibles y la garantía de que las penas no solo han de ser proporcionales en sentido estricto, sino que han de tener una finalidad de reintegración social y las subsecuentes prohibiciones específicas de imponerlas como apremios ilegítimos, tratamientos forzados, sobre la base de un mero incumplimiento contractual y de la confiscación como pena que afecta a terceros.

Desde este punto de vista, es posible afirmar que la legitimidad (validez), interpretación y aplicación del derecho penal depende, positiva y negativamente, de su correspondencia con los principios constitucionales de legalidad, proporcionalidad, culpabilidad y debido proceso. Y sostener que por esa dependencia es posible controlar la aplicación e interpretación de las leyes penales no solo por los tribunales ordinarios, sino también por el TC, a pesar de las dificultades, contradicciones y decepciones que ello ha supuesto en la práctica (Díez-Ripollés, 2013, p. 253). 
Además, atendido que el artículo 5 CPR limita la soberanía estatal obligando a los órganos del Estado a respetar el contenido de los derechos esenciales que emanan de la naturaleza humana, garantizados no solo por la Constitución, sino también por los tratados internacionales ratificados por Chile y que se encuentran vigentes, las limitaciones de los principios de legalidad, reserva y debido proceso deben entenderse referidas también al contenido de dichos tratados. De particular importancia en este aspecto es la $\mathrm{CADH}$, a cuyo órgano jurisdiccional, la Corte Interamericana de derechos Humanos, se le ha concedido la autoridad de interpretación obligatoria y sus decisiones se han estimado por nuestros tribunales de obligatorio cumplimiento (3).

De este modo, el derecho penal no se presenta como una "restricción de derechos", cuya existencia absoluta sea anterior al derecho positivo, sino como un instrumento legítimo para lograr los fines constitucionales, en la medida que su empleo sea democráticamente acordado, con pleno respeto de los principios de legalidad, proporcionalidad, culpabilidad y debido proceso.

Ello no significa, sin embargo, que a partir de finalidad de protección de derechos fundamentales se puedan derivar supuestas obligaciones de establecer determinados delitos, de carácter absoluto y sin sujeción a la deliberación democrática y a dichos principios de legalidad, reserva y del debido proceso. Este parece ser el caso de las pretensiones de algunas organizaciones internacionales y locales que abogan por la protección penal de determinados intereses que asocian al ejercicio o desarrollo de ciertos derechos fundamentales, de manera absoluta y preferente. A nuestro juicio, no hay razón lógica que justifique este predicamento, pues de la existencia de finalidades constitucionales legítimas no se deriva que el único instrumento para alcanzarlas sea el derecho penal, a menos que estemos ante regulaciones internacionales y constitucionales expresas (como las que se refieren al terrorismo y su sanción penal). La crítica liberal, según la cual este procedimiento supone una "inversión" de la función limitadora del derecho penal que se atribuye a la Constitución tiene aquí razón (Bascuñán, 2007, p. 51) (4).

Finalmente, la garantía del debido proceso se expresa en el artículo 19 № 3 CPR, cuando establece el derecho a la defensa letrada (inc. 4), el del juez natural (inc. 5) y la garantía de que toda sentencia "debe fundarse en un proceso previo legalmente tramitado", que cuente con "las garantías de un procedimiento y una investigación racionales y justos". Esas garantías, por remisión del artículo 5 inc. 2 CPR se encuentran explicitadas en los artículos 14 del Pacto Internacional

(3) Corte Suprema (2016). Rev. de Ciencias Penales 44, № 1 (p. 87), con nota aprobatoria de F. Gómez.

(4) En el mismo sentido, Mañalich (2005, p. 245). Más críticamente, Pastor (2005), caracteriza esta tendencia como "neopunitivismo" y le atribuye el desprestigio de la noción de Derechos Humanos. 
de Derechos Civiles y Políticos (PIDCP) y 8 CADH, y entre ellas se cuentan el derecho a conocer los cargos, presentar pruebas de descargos, recurrir de los fallos desfavorables, etc. La infracción de estas garantías puede acarrear la exclusión de pruebas (artículo $276 \mathrm{CPP}$ ) o la nulidad del juicio (artículo 373 a) CPP), con total independencia de la responsabilidad que sobre los hechos que se trate tenga el imputado. En la práctica, las garantías del debido proceso irradian otras, como la de la libertad personal (artículo 19 No $7 \mathrm{CPR}$ ) y la de la inviolabilidad de la morada y las comunicaciones privadas (artículo 19 № 5), cuya infracción también puede producir el efecto de declarar ilegal una detención (artículo 95 CPP) y excluir los medios de pruebas que así se hayan obtenido (artículo 276 CPP).

Pero también se incurre en una desviación de las finalidades y principios constitucionalmente reconocidos cuando, por su sola necesidad de protección, se admite la legitimidad de disposiciones que infringen los principios de legalidad, reserva o debido proceso. Esto es lo que, lamentablemente, ocurrió entre nosotros cuando el TC enarboló principios tales como la seguridad de la paz social o el interés preferente del menor para declarar conformes a la Constitución el establecimiento del delito de hurto de energía eléctrica por un DFL y no por una ley propiamente tal, así como el castigo discriminatorio de la homosexualidad masculina en el delito de sodomía del artículo 365, infringiéndose los principios de legalidad y reserva, respectivamente (Fernández C., 2015, p. 92).

No obstante, frente a estas dificultades, explicables sin duda por el carácter político del debate sobre el contenido de la legislación y su control, habrá que convenir en el hecho de que, aun así, la perspectiva constitucional, mediante el empleo de las acciones constitucionales que existen en el derecho positivo está en mejor pie para discutir la legitimidad y validez de ciertas actuaciones estatales en la creación y aplicación de las normas penales que la perspectiva tradicional(5).

\section{Función de las penas y prevención especial positiva como única finalidad constitucionalmente reconocida de las penas privativas de libertad}

\section{III.1. Función normativa de las penas. La prevención especial positiva}

En cuanto a la finalidad de las penas, la doctrina dominante, básicamente debido a su tradición histórica, previa y por tanto alejada del proceso de constitucionalización del derecho en el cambio de siglo, ha procurado determinar su legitimidad

(5) No obstante, existe doctrina moderna en contra de esta opinión, quienes afirman que ninguna de estas dos perspectivas puede superar la barrera de la ineludible discusión política subyacente en la decisión de criminalizar o no un determinado hecho (Wilenmann, 2017, p. 427). 
entendiendo su imposición como ejercicio del poder punitivo o ius puniendi, a partir de diferentes criterios (retribución, prevención general, prevención especial y todas las variantes de cada una de estas formulaciones básicas), aparentemente ajenos al régimen político en que se vive y con pretensión de universalidad.

Con carácter general, sin embargo, estas doctrinas con pretensión de validez universal y ajenas a los fundamentos constitucionales de una sociedad democrática moderna deben rechazarse, pues como lo demuestra la experiencia histórica en Alemania, ellas bien pueden llevar al extremo de considerar materialmente legítimo el derecho penal de una dictadura tan atroz como la nacionalsocialista (1933-1945), por compartir y considerar válidos sus fundamentos ideológicos, como sostuvo la inmensa mayoría de la doctrina penal alemana de la época (Rüping, 2007, p. 1009). Por otra parte, todas ellas comparten la idea iusnaturalista de que es posible determinar la existencia de hechos que deben calificarse como delito sin atención al proceso democrático (mala in se) y otros que, provenientes del mismo, deben rechazarse por carecer de similar fundamento (mala quia prohibi$t a$ ), propia del derecho común previo a la codificación y que, de manera relevante, subsiste en el common law y parece encontrarse en el fondo de las discusiones que - provenientes de la tradición filosófica angloamericana- recurren a ideas morales para fundamentar del derecho penal, sea a través del descubrimiento de una verdad universal o de alcanzar un consenso social que no necesitaría ser expresado legalmente, sino, a lo sumo, declarado por la ley (Wolfe, 2006).

Sin embargo, en sentido estrictamente normativo una pena es la "consecuencia jurídica que se impone a una persona que ha cometido un delito" (Ortiz y Arévalo, 2013, p. 17). Por tanto, la primera función de las penas es calificar un hecho determinado como delito, pues solo los delitos las contemplan como consecuencias jurídicas.

En consecuencia, como los delitos, solo son legítimas las penas establecidas con estricta sujeción al principio de legalidad, respetando los principios de proporcionalidad, culpabilidad y el debido proceso.

En cuanto a su naturaleza, la Constitución y los tratados internacionales reconocen diferentes clases de penas, cuya imposición resulta, por ello, legítima en principio: 1) inhabilidades para ejercer cargos públicos; la enseñanza; explotar o dirigir medios de comunicación y ser dirigente de organizaciones políticas o gremiales (artículo $9 \mathrm{CPR}$, en relación con los delitos terroristas); 2) pérdida de la nacionalidad, en caso de prestación de servicios durante una guerra exterior a enemigos de Chile o de sus aliados (artículo 11, N. ${ }^{\circ} 2 \mathrm{CPR}$ ); 3) pérdida de la calidad de ciudadano, en casos de delitos castigados con penas aflictivas, esto es, privativas de libertad de más de tres años de duración (artículo 17 N.o 3 CPR); 4) pena de muerte, en caso de aprobarse por ley de quórum calificado (artículo 19 N. ${ }^{\circ} 1$ 
inc. 3) (6); 5) restricción de la libertad personal (artículo 19 N. 7 b) CPR); 6) privación de libertad personal en lugares públicos (artículo 19 N. ${ }^{\circ} 7$ b) y d) CPR); 7) incomunicación con personas ajenas al establecimiento (artículo 19 N.o 7 d) CPR); 8) comiso (artículo $19 \mathrm{~N} .{ }^{\circ} 7 \mathrm{~g}$ ) CPR); 9) confiscación de bienes de sociedades ilícitas (artículo 19 N. $7 \mathrm{~g}$ ) CPR); 10) pérdida de derechos patrimoniales (multas), excepto la de los derechos previsionales (artículo 19 N. ${ }^{\circ} 7 \mathrm{~h}$ ) CPR); y 11) trabajos forzados acompañados de prisión (artículo 8.3 b) PIDCP y 6.3 a) CAHD). En el sistema penal de adultos, las penas que se pueden imponer se encuentran precisadas, con carácter general, en el artículo $21 \mathrm{CP}$ y en la ley 18.216, sobre penas sustitutivas. Además, para los adolescentes y las personas jurídicas existen sistemas sancionatorios específicos, contemplados en las leyes 20.084 y 20.393, respectivamente.

Sin embargo, la privación de derechos y la imposición de multas también pueden ser consecuencias jurídicas previstas por la legislación para ser impuestas por los órganos de la administración del Estado y no como consecuencia jurídica de un delito. Por ello, es preciso destacar que cuando hablamos de derecho penal, hoy en día hablamos principalmente de leyes que amenazan con penas privativas de libertad, las que "constituyen prácticas ampliamente aceptadas como legítimas por la comunidad internacional" y son "un elemento común a casi todos los sistemas penales" (Rodley, 1997, p. 6). Ello es coincidente con lo expresado por nuestro TC en el sentido de que lo propiamente penal son las privaciones de libertad con carácter sancionatorio, esto es, las que no están destinadas al cumplimiento de una obligación que requiere la presencia del privado de libertad, como los apremios para comparecer en juicio, de manera que solo una disposición legal de carácter penal podría imponer penas privativas de libertad(7).

Pero no basta que las penas estén establecidas legalmente para ser constitucionalmente legítimas: los Tratados Internacionales sobre Derechos Humanos obligan a orientar su ejecución hacia la prevención especial positiva. Así, mientras el artículo 10.3 PIDCP establece que "el régimen penitenciario consistirá en un tratamiento cuya finalidad esencial será la reforma y la readaptación social de los penados", el artículo 5.6 CADH dispone que "las penas privativas de libertad tendrán como finalidad esencial la reforma y la readaptación social de los condenados". Ello no solo importa la necesidad de proveer sustituciones de las penas privativas de libertad por otras sanciones que favorezcan la reintegración social (ley 18.216), sino también contar con régimen penitenciario que prepare al condenado para la libertad mediante una "acción educativa necesaria para la reinserción social"

(6) No obstante, la derogación de la pena de muerte en los delitos comunes hace imposible su restablecimiento en Chile, según lo dispuesto en el art. 4 de la Convención Americana de Derechos Humanos.

(7) Tribunal Constitucional, 21/10/2010, Rol 1518. 
(artículo 1 Reglamento de Establecimientos Penitenciarios), contemple la reducción de condenas por buena conducta y un régimen progresivo de salidas previas hasta su libertad condicional (Decreto Ley 321), excluyendo del sistema aquellas penas que pudieran producir por sí mismas efectos desintegradores o dificultaren gravemente la reinserción social.

Luego, en nuestro sistema constitucional, para ser legítima toda pena privativa de libertad ha de tener como finalidad la prevención especial positiva, esto es, ofrecer tratamientos de reintegración social a los condenados, que permitan disminuir los efectos desocializadores de la privación de libertad y faciliten su reinserción al término de la condena, reduciendo la probabilidad de reincidencia. Se trata de una orientación en que la resocialización no se entiende como "imposición de un determinado esquema de valores u orden social, sino como la creación de las bases para la autorrealización o autodesarrollo libre del individuo o, al menos, como la remoción de las condiciones que impidan que el sujeto vea empeorado, a consecuencia de la intervención penal, su estado de socialización" (Durán, 2015, p. 298).

Contra esta constatación normativa de orden superior no vale el argumento de que la función resocializadora no sería posible frente a "los delincuentes de cuello blanco, quienes se alzan en armas contra el gobierno legítimo sin conseguir su propósito de derrocarle, o el sujeto de una infidelidad diplomática o el juez que en un tribunal supremo admite una dádiva", los que no requerirían resocialización (Rivacoba, 1995, p. 143). En efecto, tales personas, si bien no se encuentran limitadas psicológica o socialmente, sí pueden presentar rasgos de personalidad, hábitos, destrezas, cargos, profesiones y relaciones que hagan más probable su reincidencia y a los cuales deba apuntar un programa de reintegración social para evitarla. Esta función de resocialización de las penas concretamente impuestas, entendida como oferta de oportunidades para la autorrealización fuera del delito, es incluso aceptada como legítima por alguna parte de la doctrina que defiende ideas más bien retribucionista sobre la legitimidad de su imposición(8).

Siendo la resocialización la finalidad legítima de las penas privativas de libertad, su sustitución por otras restrictivas de libertad y derechos, como las contempladas en la ley 18.216 (probation), es también legítima, en la medida que dicha sustitución se encuentre orientada a la reintegración social del condenado. Lo mismo vale para las salidas al exterior y otros beneficios durante la ejecución de la pena privativa de libertad, la reducción de la duración y su cumplimiento en

(8) Así, por ejemplo, se afirma "que las reglas que determinen el destino de los penados en el sistema chileno deben tener por sentido posibilitar el aprendizaje o la opción moral de los penados de alejarse de una carrera criminal" (Valenzuela, 2010, p. 266). 
libertad (parole). Pero el principio de resocialización exige también "la adopción de medidas que van más allá de la ejecución de la pena, por ejemplo, el término del sistema de antecedentes penales y otros que impliquen efectos estigmatizantes y discriminadores" (Durán, 2008, p. 71).

Otra consecuencia de la exigencia normativa de que las penas privativas de libertad tengan como finalidad la reintegración social del condenado es que las penas perpetuas que no contemplen mecanismos de libertad condicional o similares que permitan su revisión deben considerarse inconstitucionales. En Alemania y España, donde también rige el PIDCP, así lo ha declarado su jurisprudencia constitucional(9). Entre nosotros, las penas privativas de libertad perpetuas, aún en su forma más grave (presidio perpetuo calificado, artículo 32 bis), al permitir ciertas formas de revisión jurisdiccional para conceder la libertad condicional del condenado parecen encontrarse en el límite de lo admisible, aunque son discutibles las limitaciones sobre la base de un tiempo fijo de cumplimiento de pena (20 o 40 años, según los casos) o la naturaleza de los delitos cometidos (Cúneo, 2016, p. 2). De lege ferenda, la doctrina nacional rechaza de plano las penas perpetuas, estimando alrededor de 15 años el tiempo máximo de privación de libertad para que pueda cumplirse la función resocializadora (Etcheberry, 2014, pp. 113 y 121).

No obstante, siendo la orientación a la prevención especial positiva o reintegración social una finalidad material y normativamente reconocida de las penas privativas de libertad, no es exigible en cuanto a sus resultados sino en su establecimiento, imposición y formas de ejecución, pues lograr la efectiva reintegración de un condenado, esto es, conseguir su retraimiento de la actividad criminal tras el cumplimiento de la pena, depende de muchos factores sociales e individuales que los encargados del sistema penitenciario no están en condiciones de controlar o modificar.

Con todo, se debe dejar constancia del avance de las ciencias conductuales en esta materia, que ha dejado de lado el pesimismo de los años 70 (10) para dar paso a un moderado optimismo en las posibilidades de la reintegración social mediante tratamientos y modificaciones conductuales voluntarias y efectivas (Dropelmann, 2010, p. 3). Entre ellos se encuentran, por ejemplo, experiencias de rehabilitación y reducción efectivas de la reincidencia mediante programas de meditación trascendental, cuya eficacia ha sido demostrada incluso en internos de cárceles de alta seguridad, como el penal de Folsom en Estados Unidos (Rainforth y Cavanaugh,

(9) Sentencias del Tribunal Constitucional de Alemania de 21/6/1977, Rol 14/76, y del Tribunal Constitucional de España de 30/3/2000, Rol 91/2000.

(10) Cuyo epítome es el eslogan del nothing works, extraído como conclusión del texto de Martinson (1974, p. 22).

Revista Anales de la Facultad de Ciencias Jurídicas y Sociales. Universidad Nacional de La Plata. UNLP.

Año 18/№ 51-2021. Anual. Impresa ISSN 0075-7411-Electrónica ISSN 2591-6386 
2003, p. 181). Otros programas respaldados con la evidencia son los tribunales de tratamiento de drogas, los basados en el paradigma riesgo-necesidad-respuesta, los de distanciamiento y reinserción al momento del egreso, etc. (Lipsey y Cullen, 2007, p. 297).

\section{III.2. Funciones empíricas de las penas privativas de libertad: prevención especial negativa (aseguramiento), prevención general (disuasión) y cohesión social (prevención general social). Su limitación por la finalidad de prevención especial positiva}

Cuando los tratados y la Constitución admiten como legítimas las penas privativas de libertad orientadas hacia la reintegración social de los condenados, admiten también los eventuales efectos empíricamente contrastables de dicha privación de libertad: el aseguramiento del condenado (prevención especial negativa) y la disuasión de terceros (prevención general). El aseguramiento, que puede fundamentarse filosóficamente en el argumento de la persistencia de los estados de las cosas mientras no se produzca un cambio real (Descartes, 1977, p. 9), es la exclusión de los condenados de la vida social por un tiempo determinado, impidiéndoles o dificultándoles la reiteración delictiva (Levitt, 1996, p. 319). Y la disuasión de terceros es el resultado de la combinación de las probabilidades de aprehensión y condena y la gravedad de las penas en el comportamiento general de la población (Becker, 1968, p. 204).

Por otra parte, los estudios conductuales han demostrado que la imposición de penas privativas de libertad apropiadas no solo disuade, sino también mantiene el comportamiento cooperativo (Balliet; Mulder y Lange, 2011, p. 600). Esta constatación empírica ha llevado incluso a la formulación de un criterio de legitimación del sistema penal diferente a los tradicionales: la prevención general social (Rodríguez, 2017, p. 62).

Sin embargo, todas las consecuencias empíricas de las sanciones son eventuales, pues su efectiva imposición y la forma concreta en que ello se hace depende de los recursos destinados tanto al sistema de persecución criminal como al penitenciario. Un sistema penitenciario cuya organización no evite la comisión de delitos al o desde el interior de los recintos carcelarios, no solo impide la reintegración social, sino que genera un efecto menor de aseguramiento y una mayor desintegración, al incorporar a los internos a redes y organizaciones criminales, como sucede en buena parte de las cárceles latinoamericanas (Dudley y Bargent, 2017, p. 4). Y un sistema de persecución penal con una baja probabilidad de condena por los delitos que conoce (o que asegura una pena desproporcionadamente baja en comparación con la ganancia que reporta el delito) no disuade y puede hasta considerarse un factor que induce a la actividad criminal (Bentham, 1826, p. 26). 
Finalmente, un sistema que permite a muchos free riders salir permanentemente con la suya, produce desazón social y la pérdida de respeto por la ley, a pesar de que algunos pocos sean efectivamente sancionados (Akerlof y Shiller, 2009, pos. 906).

Por otra parte, el aseguramiento, la disuasión y la integración social como efectos empíricos de la imposición de penas privativas de libertad, no se legitiman por sí mismos, sino que su legitimidad proviene de la de estas: una pena que solo asegure al condenado sin ofrecer tratamientos o formas de ejecución orientadas a su resocialización o que consista en su aseguramiento a través de su incapacitación corporal, no será legítima. Y tampoco será legítima la disuasión o la cohesión social intentadas sancionando con penas que no estén orientadas a la reintegración social.

\section{Bibliografía}

Akerlof, R. y Shiller, R. (2009). Animal Spirits: Cómo influye la psicología humana en la economía. Kindle: Gestión 2000.

Balliet, D.; Mulder, L. y Lange, P. (2011). Reward, Punishment, and Cooperation: A Meta-analysis. Psychological Bulletin, 137 (4) (pp. 594-615).

Bascuñán, A. (2007). Derechos fundamentales y derecho penal. Revista de Estudios de la Justicia, 9 (pp. 47-74).

Beccaria, C. (1774). De los delitos y de las penas. Madrid: Imp. Joachin Ibarra.

Becker, G. (1968). Crime and Punishment: An Economic Approach. Journal of Political Economy, 76 (2) (pp. 169-217).

Bentham, J. (1826). Teoría de las Penas y de las Recompensas, tomo I. Paris: D.L.B.

Bricola, F. (1973). Teoria Generale del Reato. Novissimo Digesto Italiano, T. XIX (pp. 7-93). Turín: Utet.

Cúneo, S. (2016). Prisión perpetua y dignidad humana. Una reflexión tras la muerte de Manuel Contreras. Política Criminal 11 (21) (pp. 1-20).

Cury, E. (2020). Derecho Penal, Parte General, tomo I. Santiago: Ed. P. U. Católica de Chile.

Descartes, R. (1977). Meditaciones metafísicas. Primera meditación. Madrid: Alfaguara. 
Díez-Ripollés, E. (2013). La racionalidad de las leyes penales, 2a Ed. Madrid: Trotta.

Donini, M. (2011). La herencia de Bricola y el constitucionalismo penal como método. Raíces nacionales y desarrollos supranacionales. Nuevo Foro Penal, 7 (77) (pp. 45-83).

Dropelmann, C. (2010). Elementos claves en la rehabilitación y reinserción de infractores de ley en Chile. Conceptos (Fundación Paz Ciudadana), 14 (pp. 1-15).

Dudley, S. y Bargent, J. (2017). El dilema de las prisiones: incubadoras del crimen organizado en Latinoamérica. InSight Crime, 20 de enero de 2017. Recuperado de https://es.insightcrime.org/investigaciones/dilema-prisiones-incubadoras-crimen-organizado-latinoamerica/ [Fecha de consulta: 20/09/2021].

Durán, M. (2008). Prevención especial e ideal resocializador. Concepto, evolución y vigencia en el marco de la legitimación y justificación de la pena. Revista de Estudios Criminológicos y Penitenciarios, 8 (13) (pp. 57-80).

Durán, M. (2011). Constitución y legitimación de la pena: Apuntes teleológicos sobre el rol de la Constitución en el sistema penal. Política Criminal 6 (11) (pp. 142-162).

Durán, M. (2015). Constitución penal y teoría de la pena: apuntes sobre una relación necesaria y propuesta sobre un posible contenido desde la prevención especial. Revista Fundamentación Jurídica Díkaion, 24 (2) (pp. 282-306).

Etcheberry, A. (1998). Derecho Penal, tomo I. Santiago: Ed. Jurídica de Chile.

Etcheberry, A. (2011). Introducción. En Matus, J. P. (Dir.), Beccaria, 250 años después (pp. 1-12). Buenos Aires: BDF.

Etcheberry, A. (2014). Cambios necesarios en la función y enfoque de las penas privativas de libertad. En Rodríguez L. A. (ed.), Algunas visiones del derecho penal hoy. Santiago: Ed. U. Santo Tomás.

Fernández Cruz J. A. (2010). El juicio constitucional de proporcionalidad de las leyes penales: ¿la legitimación democrática como medio para mitigar su inherente irracionalidad? Revista de Derecho (Coquimbo), 17 (1) (pp. 51-99).

Fernández Cruz J. A. (2015). Principialismo, garantismo, reglas y derrotabilidad en el control de constitucionalidad de las leyes penales. Nuevo Foro Penal, 11 (85) (pp. 52-78). 
Fernández González M. A. (2006). La nueva justicia penal frente a la Constitución. Santiago: Lexis Nexis.

Levitt, S. (1996). The Effect of Prison Population Zise on Crime Rates: Evidence from Prison Overcrowding Litigation. Quarterly Journal of Economics 111 (2) (pp. 319.351).

Lipsey, M. y Cullen, F. (2007). The Effectiveness of Correctional Rehabilitation: A Review of Systematic Reviews. Annual Review of Law Social Sciences 3 (pp. 297-320).

Lorca, R. (2019). La presunción de castigo. Una revisión crítica de sus orígenes en el pensamiento de la modernidad temprana. En Letra: Derecho Penal 5 (8) (pp. 178-206).

Mañalich, J. P. (2005). La prohibición de infraprotección como principio de fundamentación de normas punitivas ¿Protección de los derechos fundamentales mediante el derecho penal? Revista Derecho y Humanidades, 11 (pp. 245-258).

Martinson, R. (1974). What Works?-Questions and Answers about Prison Reform. Public Interest 35 (pp. 22-54).

Matus, J. P. (2018). La Ley penal y su Interpretación, 3. a ed. Santiago: Olejnik.

Matus, J. P. y Ramírez. M. C. (2015). Lecciones de Derecho penal chileno. Fundamentos y limites constitucionales del Derecho penal positivo. Santiago: Thomson Reuters.

Matus, J. P. y Ramírez. M. C. (2021). Manual de Derecho Penal Chileno. Valencia: Tirant Lo Blanch.

Mera, J. (2005). Derechos Humanos en el derecho penal chileno. Santiago: Lexis Nexis.

Novoa, E. (1987). Cuestiones de derecho penal y criminología. Santiago: Bat.

Ortiz, L. y Arévalo, J. (2013). Las consecuencias jurídicas del delito. Santiago: ed. Jurídica de Chile.

Pastor, D. (2005). La deriva neopunitivista de organismos y activistas como causa del desprestigio actual de los derechos humanos. Nueva Doctrina Penal 2005/A (pp. 73-114).

Piña, J. I. (2005). Rol social y sistema de imputación. Una aproximación sociológica a la función del derecho penal. Barcelona: Bosch. 
Politoff, S. (1978). Justicia y fascismo. Araucaria de Chile 3 (pp. 3-10).

Rainforth, A. y Cavanaugh, K. (2003). Effects of the Transcendental Meditation Program on Recidivism Among Former Inmates of Folsom Prison. Journal of Offender Rehabilitation 36 (1-4) (pp. 181-203).

Rivacoba, M. (1995). La retribución penal. Santiago: Conosur.

Rodley, N. (1967). Informe sobre la cuestión de los derechos Humanos de todas las personas sometidas a cualquier forma de detención o prisión y, en particular: la tortura y otros tratos o penas crueles, inhumanos o degradantes. E/CN.4/1997/7, Naciones Unidas. Recuperado de https://www.acnur.org/fileadmin/Documentos/BDL/2001/1553.pdf [Fecha de consulta: 20/09/2021].

Rodríguez H. D. (2017). Comportamiento humano y pena estatal: disuasión, cooperación y equidad. Madrid: Marcial Pons.

Rüping, H. (2017). Nationalsozialismus und Strafrecht. Quaderni Fiorentini per la Storia del Penseiro Giuridico Moderno 36 (2) (pp. 1007-1030).

Valenzuela, J. (2010). La pena como penitencia secular. Apuntes sobre el sentido de la ejecución de la pena. Revista de Derecho (Valdivia) 23 (1) (pp. 255-268).

Wilenmann, J. (2017). Control institucional de decisiones legislativas políticocriminales. Revista Estudios Constitucionales 15 (2) (pp. 389-446).

Wolfe, N. (2006). Mala in se, a dissapearing doctrine? Criminology, 19 (1) (pp. 131-143).

Fecha de recepción: 30-03-2021

Fecha de aceptación: 20-09-2021 
